Supporting Information to

\title{
pH-Responsiveness of Block Copolymer Vesicles With a Polypeptide Corona
}

\author{
Reinhard Sigel, Magdalena Łosik, and Helmut Schlaad* \\ Max Planck Institute of Colloids and Interfaces, Colloid Department, \\ Research Campus Golm, 14424 Potsdam, Germany
}

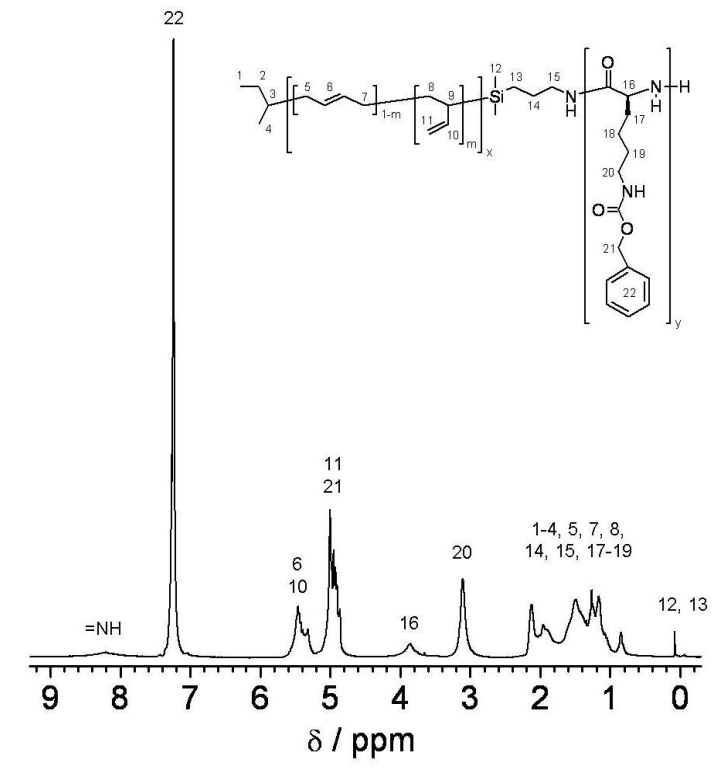

Figure SI-1. ${ }^{1} \mathrm{H}$ NMR $\left(400.1 \mathrm{MHz}, \mathrm{CDCl}_{3}\right)$ spectrum of $\mathrm{PB}_{165}-b$-PZLLys 88 .

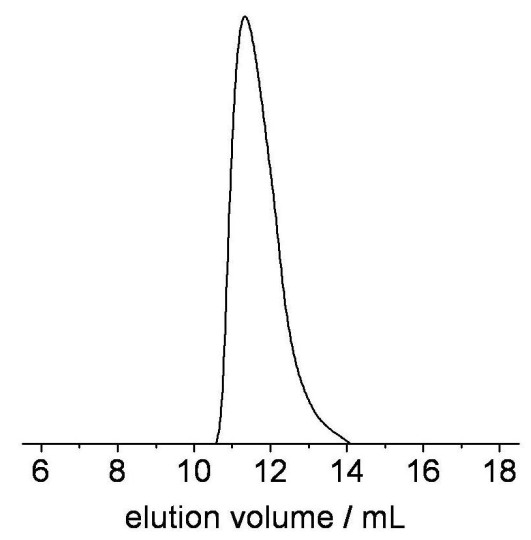

Figure SI-3. SEC trace of $\mathrm{PB}_{165}-b$-PZLLys 88 . Eluent: $N$-methyl-2-pyrrolidone (NMP) +0.5 wt \% LiBr; flow rate: $0.8 \mathrm{~mL} / \mathrm{min}$ at $70{ }^{\circ} \mathrm{C}$; columns: two $300 \times 8$ $\mathrm{mm}$ columns filled with $5 \mu \mathrm{m}$ PS particles (pore size: $10^{2}-10^{5} \AA$ ); detector: RI.

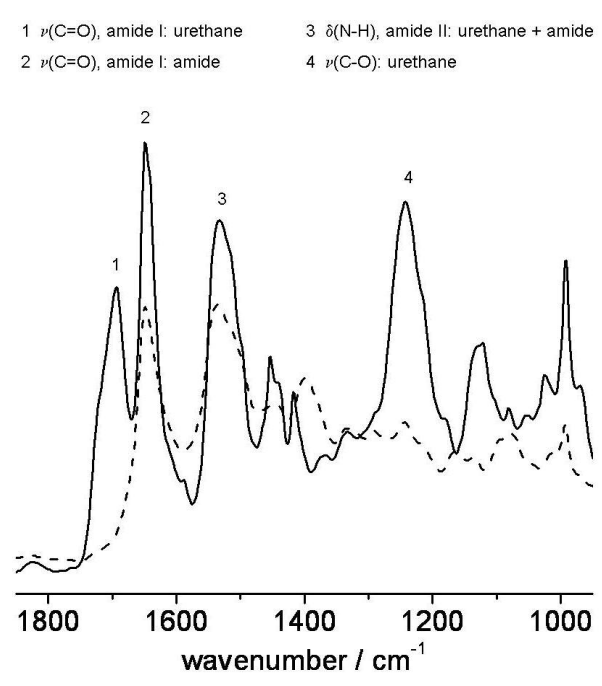

Figure SI-2. FT-IR spectra of $\mathrm{PB}_{165}-b$-PZLLys 88 (solid line) and $\mathrm{PB}_{165}-b-\mathrm{PLLys}_{88}$ (dashed line). 

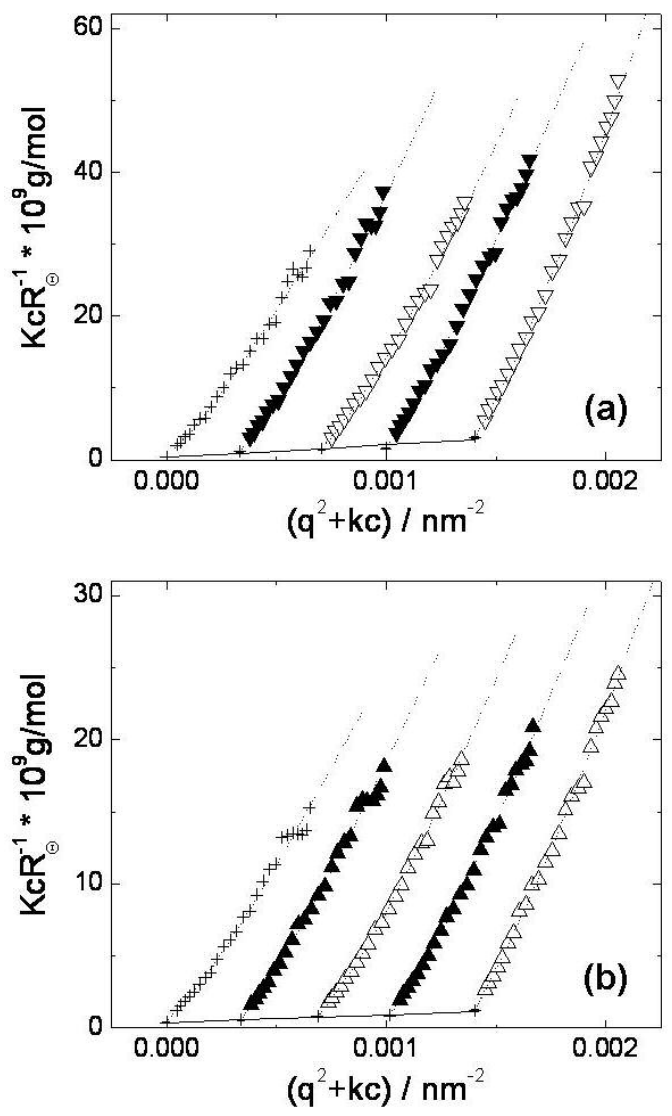

Figure SI-4. SLS: Static Zimm plots of aqueous saline solutions of $\mathrm{PB}_{165}-b$-PLLys 88 at $\mathrm{pH} 7.0$ (a) and $\mathrm{pH} 10.3$ (b).
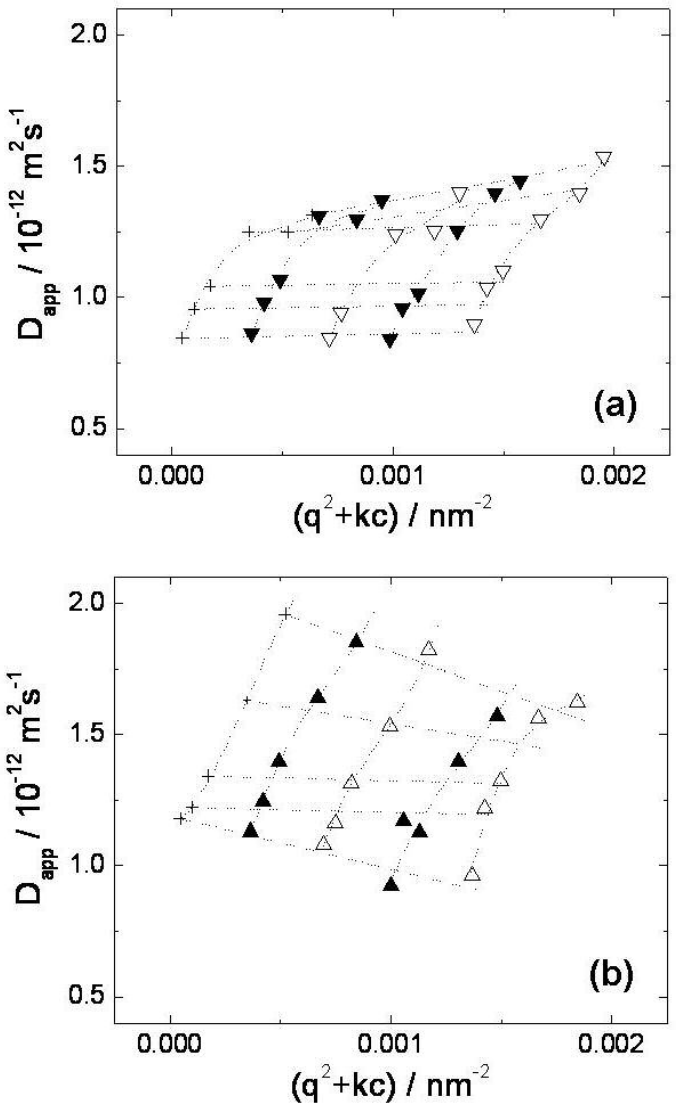

Figure SI-5. DLS: Dynamic Zimm plots of aqueous saline solutions of $\mathrm{PB}_{165}-b$-PLLys 8 at $\mathrm{pH}$ 7.0 (a) and $\mathrm{pH} 10.3$ (b). 